\title{
Chapter 12 \\ Dynamic Response Analysis of Floating Wind Turbines with Emphasis on Vertical Axis Rotors
}

\author{
Zhengshun Cheng, Torgeir Moan, and Zhen Gao
}

\begin{abstract}
Large floating wind turbines are feasible for offshore application. Due to the commercial success onshore and nearshore, floating horizontal axis wind turbines (HAWTs) are now being widely studied. However, floating vertical axis wind turbines (VAWTs) have an excellent potential in the cost of energy reduction compared with floating HAWTs. This paper deals with the integrated modeling and dynamic response analysis of typical floating VAWT concepts. A fully coupled aero-hydro-servo-elastic method is presented for numerical modeling and dynamic response analysis of floating wind turbine systems. Considering a two-bladed $5 \mathrm{MW}$ Darrieus rotor, the dynamic response characteristics of typical floating VAWT concepts are studied. In addition, comparative studies of floating HAWTs and VAWTs are performed.
\end{abstract}

\subsection{Introduction}

During the 1970s and 1980s, a large amount of efforts was devoted to develop VAWTs, particularly in the United States and Canada. However, the VAWTs gradually lost the competition with the horizontal axis wind turbines (HAWTs) due to low efficiency and fatigue problems within the bearings and blades. In recent years, offshore wind farms are moving towards deeper waters where floating wind turbines are required in countries such as the Japan, Norway and United States. Due to the commercial success onshore and nearshore, floating HAWTs are now being widely studied and prototypes have been developed and tested, such as the Hywind demo in Norway, the WindFloat demo in Portugal and the floating wind turbines off the Fukushima coast of northeast Japan.

The interest in the development of VAWTs for offshore application has also been resurging. Compared with floating HAWTs, floating VAWTs have lower centers of gravity, are independent of wind direction, can provide reduced machine complexity and have the potential of achieving more than $20 \%$ cost of energy reductions

\footnotetext{
Z. Cheng $(\bowtie) \cdot$ T. Moan $\bullet$ Z. Gao

Department of Marine Technology, Centre for Ships \& Ocean Structures (CeSOS)/Centre for Autonomous Marine Operations \& Systems (AMOS), Norwegian University of Science and Technology (NTNU), 7491 Trondheim, Norway

e-mail: zhengshun.cheng@ntnu.no; torgeir.moan@ntnu.no; zhen.gao@ntnu.no
} 
(Paquette and Barone 2012). Moreover, floating platforms can help to mitigate the fatigue damage suffered by the onshore VAWTs (Wang et al. 2016). In addition, floating VAWTs are more suitable for deploying as wind farms than floating HAWTs (Dabiri 2011). Thus, more and more efforts are devoted to the development of floating VAWTs.

In order to assess the technical feasibility of floating VAWTs, a numerical simulation tool is required to conduct the fully coupled aero-hydro-servo-elastic analysis. To date the available simulation tools that can model the floating VAWTs in a fully-coupled way are limited, but are emerging, such as the FloVAWT code by Cranfield University (Collu et al. 2013), the OWENS toolkit by Sandia National Laboratories (Brian et al. 2013), the HAWC2 by DTU Wind Energy (Larsen and Madsen 2013), the SIMO-RIFLEX-DMS (Wang et al. 2013) and SIMO-RIFLEXAC (Cheng et al. 2016b) code by NTNU. Among these codes, the aerodynamic loads are mainly computed using the double multi-streamtube (DMS) model (Paraschivoiu 2002) or actuator cylinder (AC) flow model (Madsen 1982), which are capable of predicting the aerodynamic loads accurate at a small computational cost. These two models are validated using experimental data by Wang et al. (2015b) and Cheng et al. (2016a). Code-to-code comparisons between these codes were also conducted to verify each code, such as the comparison of FloVAWT and SIMO-RIFLEX-DMS by Borg et al. (2014c), and the comparison of three codes SIMO-RIFLEX-DMS, SIMO-RIFLEX-AC and HAWC2 by Cheng et al. (2016b).

Considerable efforts have been made to study the floating VAWTs by many researchers using the aforementioned codes. Using the code HAWC2, Paulsen et al. (2013) performed a design optimization of the proposed DeepWind concept. An improved design has been obtained with an optimized blade profile with less weight and higher stiffness than the 1st baseline design. Based on the code FloVAWT, Borg et al. $(2014 \mathrm{a}, \mathrm{b})$ presented a review on the dynamic modeling of floating VAWTs, used a wave energy converter as a motion suppression device for floating wind turbines (Borg et al. 2013) and further performed a comparison on the dynamics of floating VAWTs with three different floating support structures (Borg and Collu 2014). A floating VAWT concept with a 5 MW Darrieus rotor mounted on a semi-submersible was proposed by Wang et al. (2013) and fully coupled aero-hydroservo-elastic simulations were carried out with emphasis on stochastic dynamic responses (Wang et al. 2016), effects of second order difference-frequency forces and wind-wave misalignment (Wang et al. 2015a), and emergency shutdown process with consideration of faults (Wang et al. 2014a).

In this study, dynamic response characteristics of typical floating VAWTs are addressed. The development and verification of fully coupled numerical simulation tools SIMO-RIFLEX-DMS and SIMO-RIFLEX-AC are presented. Using a twobladed $5 \mathrm{MW}$ Darrieus rotor, dynamic responses of three floating VAWT concepts (Cheng et al. 2015a, 2015c) are studied by fully coupled nonlinear time domain simulations. In addition, comparative studies of the dynamic responses of floating HAWTs with the NREL 5 MW wind turbine (Jonkman et al. 2009) and VAWTs with the 5 MW Darrieus rotor (Vita 2011) are also performed to assess the merits and disadvantages of each concept. 


\subsection{Typical Floating VAWT Concepts}

Currently several floating VAWT concepts have been proposed, including the DeepWind (Vita 2011), VertiWind (Cahay et al. 2011) and floating tilted axis (Akimoto et al. 2011) concepts. They are comprised of a vertical axis rotor, a floater and a mooring system. The rotor can be straight-bladed H-type rotor, curve-bladed Darrieus rotor, helical-bladed rotor and V-type rotor, while the floater could be a spar, semi-submersible or TLP.

Herein three floating support structures were studied: namely a spar, a semisubmersible and a TLP, as depicted in Fig. 12.1 and listed in Table 12.2. The concepts were used to support a $5 \mathrm{MW}$ Darrieus rotor, which is the baseline design developed in the DeepWind project (Vita 2011). The rotor is comprised of two blades and one rotating tower that spans from the top to the bottom that is connected to the generator. Main specifications of this rotor are summarized in Table 12.1. The generator considered here was assumed to be placed at the tower base, and the generator mass was incorporated in the platform hull mass.

The concepts were originally designed to support the NREL $5 \mathrm{MW}$ wind turbine (Jonkman et al. 2009). The concepts were considered in the water depth where they were designed, ranging from $150 \mathrm{~m}$ for the TLP, $200 \mathrm{~m}$ for the semi to $320 \mathrm{~m}$ for the spar. Here reasonable modifications were made on each platform to support the 5 MW Darrieus rotor, such as adjusting the ballast of the spar and the semi, and the tendon pretension of the TLP. For each platform, the draft and displacement were maintained the same as the original one. Details regarding the adjustment can refer to Cheng et al. (2015c). Properties related to the three floating VAWT systems are given in Table 12.2. The natural periods of rigid body motions for the floating
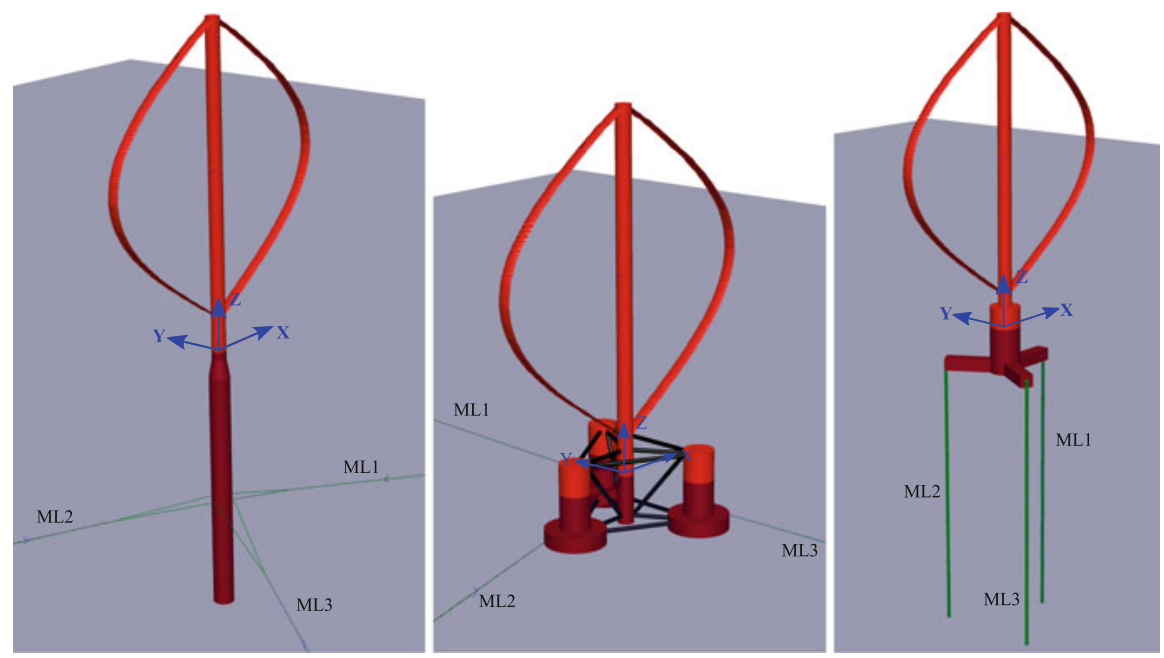

Fig. 12.1 Three floating VAWT concepts: spar, semi-submersible and TLP 
Table 12.1 Specifications of the Darrieus $5 \mathrm{MW}$ wind turbine

\begin{tabular}{l|l}
\hline & Darrieus rotor \\
\hline Rated power [MW] & 5 \\
\hline Rotor radius [m] & 63.74 \\
\hline Rotor height, root-to-root [m] & 129.56 \\
\hline Chord length [m] & 7.45 \\
\hline Cut-in, rated, cut-out wind speed [m/s] & $5,14,25$ \\
\hline Rated rotor rotational speed [rpm] & 5.26 \\
\hline Total mass, including rotor, shaft and tower [kg] & 754,226 \\
\hline Location of overall center of mass [m] & $(0,0,75.6)$ \\
\hline
\end{tabular}

Table 12.2 Properties of the three floating wind turbine systems

\begin{tabular}{l|l|l|l}
\hline Floater & Spar & Semi-submersible & TLP \\
\hline Water depth [m] & 320 & 200 & 150 \\
\hline Draft [m] & 120 & 20 & 22 \\
\hline Diameter at mean water line [m] & 6.5 & $12.0 / 6.5$ & 14.0 \\
\hline $\begin{array}{l}\text { Platform mass, including ballast \& } \\
\text { generator [ton] }\end{array}$ & 7308.3 & 13353.7 & 2771.9 \\
\hline Center of mass for platform [m] & $(0,0,-89.76)$ & $(0,0,-15.38)$ & $(0,0,-13.42)$ \\
\hline Buoyancy in undisplaced position [kN] & 80,710 & 139,816 & 56,804 \\
\hline Center of buoyancy [m] & $(0,0,-62.07)$ & $(0,0,-13.15)$ & $(0,0,-14.20)$ \\
\hline Surge/Sway natural period [s] & 130.8 & 114.0 & 45.3 \\
\hline Heave natural period [s] & 27.3 & 17.1 & 0.6 \\
\hline Roll/Pitch natural period [s] & 34.5 & 31.0 & $4.5 / 4.9$ \\
\hline Yaw natural period [s] & 8.5 & 79.7 & 19.3 \\
\hline
\end{tabular}

systems were estimated by conducting free decay tests using numerical simulations (Cheng et al. 2015c).

Since the difference in mass between the $5 \mathrm{MW}$ Darrieus rotor and the NREL 5 MW wind turbine was small compared to the displacements of these three concepts, it was assumed that such modifications would not alter the hydrostatic performance of each platform significantly, which was verified by the following simulations. After these modifications, these substructures supporting the $5 \mathrm{MW}$ Darrieus rotor may not be optimal from an economical point of view, but they are sufficient to demonstrate the inherent motion and structural response characteristics of each concept.

\subsection{Integrated Modeling of a Floating VAWT System}

A floating wind turbine system is usually comprised of a rotor harvesting wind energy, a floater supporting the rotor and a mooring system keeping the floater in position. To evaluate its performance, a fully coupled aero-hydro-servo-elastic 


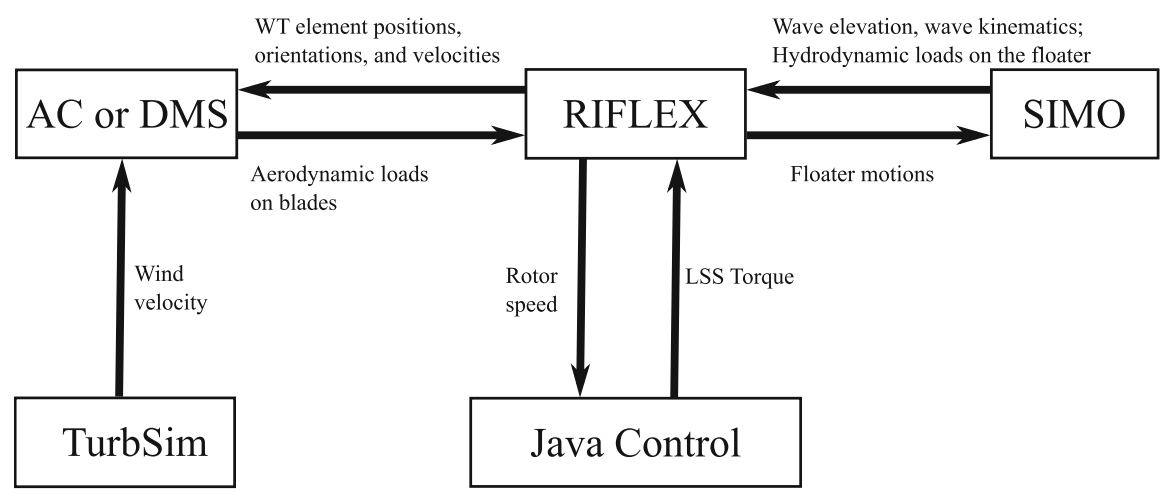

Fig. 12.2 Overview of the fully coupled aero-hydro-servo-elastic codes SIMO-RIFLEX-DMS and SIMO-RIFLEX-AC

simulation tool is required to carry out the time domain simulations similar as those used for analysis of floating HAWTs. This coupled code should account for the aerodynamics, hydrodynamics, structural dynamics, controller dynamics and mooring line dynamics. Currently, two fully coupled codes, namely SIMORIFLEX-DMS and SIMO-RIFLEX-AC, are developed in NTNU to conduct such fully integrated modeling and analysis for floating VAWTs. These two codes are based on the codes SIMO (MARINTEK 2012b) and RIFLEX (MARINTEK 2012a), which are originally developed and are now widely used in the offshore oil \& gas industry. The SIMO-RIFLEX wind turbine module has previously been verified (Luxcey et al. 2011; Ormberg et al. 2011).

As illustrated in Fig. 12.2, each coupled code integrates three computer codes, including the SIMO (MARINTEK 2012b), RIFLEX (MARINTEK 2012a) and an aerodynamic module. SIMO computes the hydrodynamic forces and moments on the floater; RIFLEX represents the blades, tower, shaft and mooring lines as nonlinear flexible finite elements and provides the links to an external controller and an aerodynamic module. Obviously, the significant difference between these two codes lies in the method used to compute the aerodynamic loads. Detailed discussions about the related aerodynamic theories are demonstrated in Sect. 12.3.1. In addition, the external controller based on two different control strategies is written in Java. In this way, each of these two fully coupled codes can provide a comprehensive aero-hydro-servo-elastic simulation tool with well-known aerodynamic module, sophisticated hydrodynamic model, stable nonlinear finite element solver, and userdefined controller.

In each fully coupled code, the blades, shaft, tower and mooring lines are modeled as nonlinear flexible finite elements while the floater is considered as a rigid body. Detailed structural model for each component and the corresponding external load models are illustrated in Fig. 12.3. The aerodynamic force is computed in the aerodynamic module as distributed lift and drag forces along the blade and then transferred from the rotor to the generator. The first- and second-order 


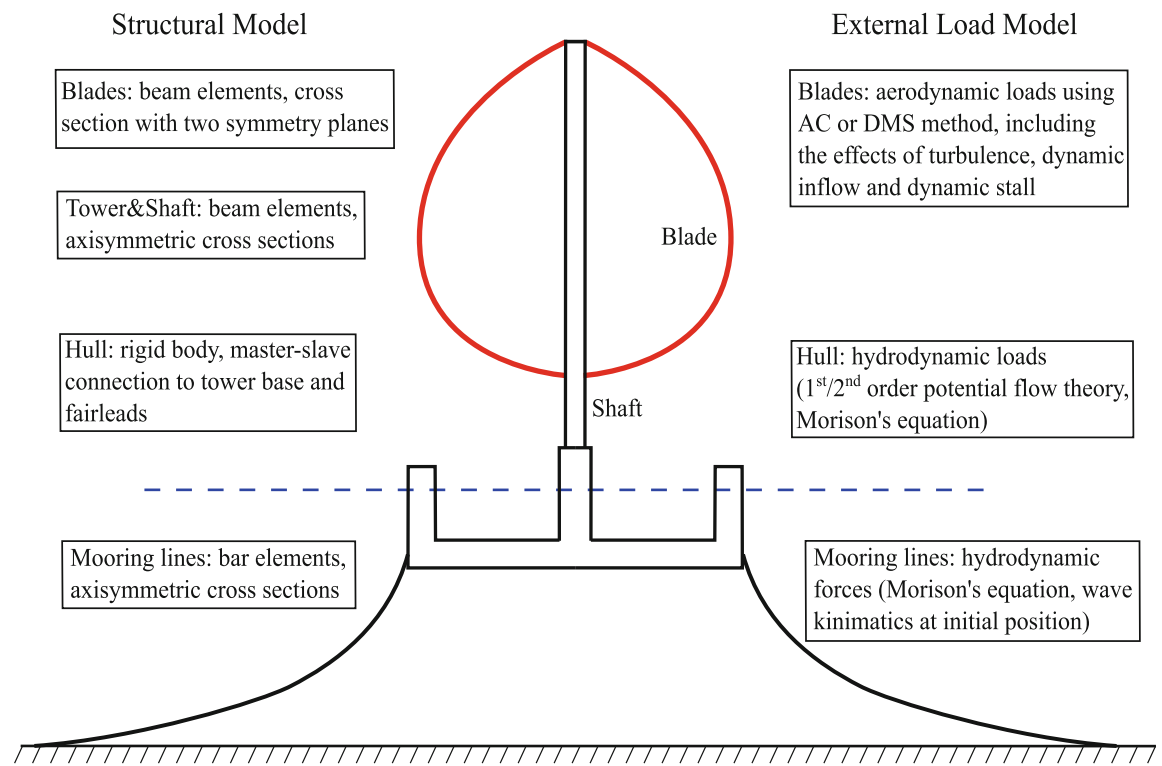

Fig. 12.3 The structural model and external force model of a floating VAWT (Cheng et al. 2016b)

wave excitation forces on the floater are pre-generated in SIMO, while the viscous drag forces on the floater are updated. At each time step, the dynamic equilibrium equations of the rotor, platform and mooring lines are solved in RIFLEX and the rotor rotational speed is regulated through the external controller. Then the platform motions are transferred to SIMO to update the viscous drag forces on the floater, while the positions, velocities and accelerations of the blade elements are transferred to the aerodynamic module to update the aerodynamic loads.

\subsubsection{Aerodynamics}

Among the aerodynamic models for VAWTs, the Double Multiple-Streamtube (DMS) model (Paraschivoiu 2002) and Actuator Cylinder (AC) flow method (Madsen 1982) are two favorable methods that are suitable for fully coupled modeling and analysis for floating VAWTs. Based on these two methods, two aerodynamic codes are developed for fully coupled modeling and analysis of floating VAWTs by Wang et al. (2015b) and Cheng et al. (2016a), respectively.

The DMS method is based on the conservation of mass and momentum in a quasi-steady flow. It assumes that the rotor is vertically divided into a series of adjacent streamtubes, within which a pair of actuator disks are used to represent the turbine. Then the forces on the rotor blades are equated to the change in the streamwise momentum through the turbine, so as to calculate the axial induction 

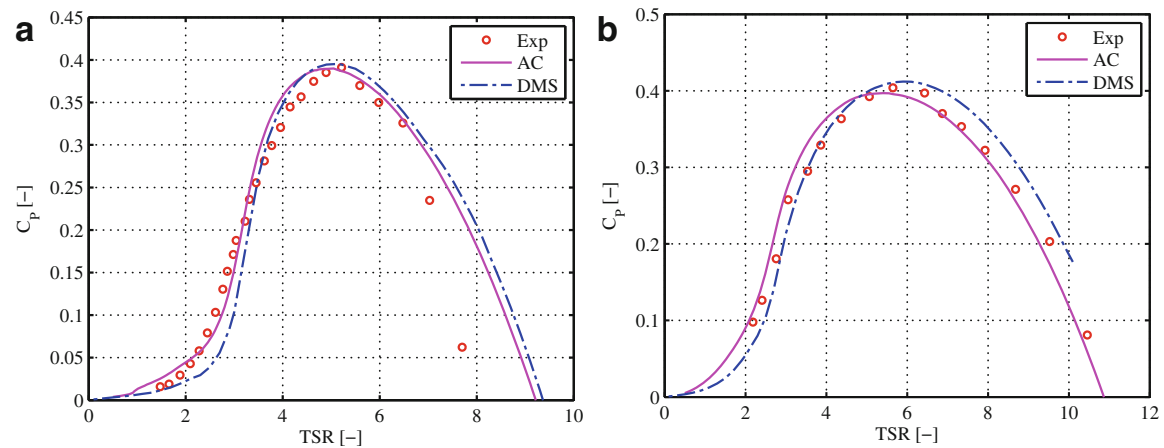

Fig. 12.4 Comparison of power coefficient curve between simulation model and experimental data. (a) The 3-bladed Sandia $5 \mathrm{~m}$ Darrieus rotor at rotational speed of $150 \mathrm{rpm}$, (b) the 2-bladed Sandia $17 \mathrm{~m}$ Darrieus rotor at rotational speed of $50.6 \mathrm{rpm}$

factor. The DMS model implemented by Wang et al. (2013) accounts for the effect of variation in the Reynolds number and incorporates the effect of dynamic stall using the Beddoes-Leishman dynamic stall model. It is validated by comparison with experimental results of the Sandia $5 \mathrm{~m}$ and $17 \mathrm{~m}$ Darrieus rotors, as shown in Fig. 12.4.

The AC method is a 2D quasi-steady flow model developed by Madsen (1982). The model extends the actuator disc concept to an actuator surface coinciding with the swept area of the 2D VAWT. In the AC model, the normal and tangential forces resulting from the blade forces are applied on the flow as volume force perpendicular and tangential to the rotor plane, respectively. The induced velocities are thus related to the volume force based on the continuity equation and Euler equation. The induced velocity includes a linear part and a nonlinear part; the linear part can be computed analytically given the normal and tangential loads. However, it's to some extent time-consuming to compute the nonlinear solution directly. A simple correction is therefore introduced to make the final solution in better agreement with the fully nonlinear solution. The developed AC model (Cheng et al. 2016a) is verified by comparison with other numerical models and experimental data, as demonstrated in Fig. 12.4. The AC model implemented in Cheng et al. (2016b) includes the effects of wind shear and turbulence, and dynamic inflow. The effect of dynamic stall is also incorporated using the Beddoes-Leishman dynamic stall model.

\subsubsection{Hydrodynamics}

The hydrodynamic loads are computed using a combination of the potential flow theory and Morison's equation. For large volume structures, the added mass, radiation damping and first order wave forces were obtained from a potential flow model 
and applied in the time domain using the convolution technique (Faltinsen 1995). When the second-order wave force becomes important for structures with natural frequencies that either very low or near twice the wave frequency, the second-order potential flow theory is applied to account for the mean drift, difference-frequency and sum-frequency wave forces using the Newman approximation or quadratic transfer function (QTF). Regarding the slender structures where the diameter D is small compared to the wavelength $\lambda$ (roughly, $\mathrm{D} / \lambda<1 / 5$ ), the Morison equation is applied to calculate the inertial load and viscous drag load (Faltinsen 1995). In addition, viscous forces on large volume structures can also be incorporated through the Morison's equation by considering only the quadratic viscous drag term.

\subsubsection{Structural Dynamics}

In the structural model, the blades are modeled as flexible beam elements with two symmetric planes to differ the flapwise stiffness and edgewise stiffness. The tower and shaft are modeled as axisymmetric beam elements while the mooring lines are considered as nonlinear bar element, as shown in Fig. 12.3. A flexible joint is used to connect the rotating part and non-rotating part within the shaft. The electric torque from the generator is also applied at this joint to regulate the rotor rotational speed according to the prescribed control strategy. Moreover, master-slave connections are applied to integrate the motions between the tower base and fairleads.

In RIFLEX, the dynamic equilibrium equations can be solved in the time domain using the Newmark- $\beta$ numerical integration $(\beta=0.256, \gamma=0.505)$. Structural damping is included through global proportional Rayleigh damping terms for all beam elements.

\subsubsection{Control System}

Considering a typical floating VAWT that operates at a fixed blade pitch angle, a generator torque controller can be used to regulate the rotational speed (Cheng et al. 2016b). The controller aims to minimize the error between the measured and filtered rotational speed $\Omega_{\text {mea }}$ and the reference rotational speed $\Omega_{\text {ref }}$ by adjusting the generator torque through a PI control algorithm.

For a typical floating VAWT system the relationship between the reference rotational speed and the wind speed is demonstrated in Fig. 12.5 (Cheng et al. 2016b). According to the operating conditions, it can be divided into three regions, as highlighted in Fig. 12.5. In region $I$ where wind speeds ranges from $V_{\text {in }}$ to $V_{\Omega N}$, the rotor operates at the optimal tip speed ratio so as to achieve the highest power coefficient. In region II, the rotor operates at a moderate tip speed ratio and holds the rotational speed constant at the rated one. The control targets in region I and II aim to maximize the power capture and at the same time keep the rotational speed 


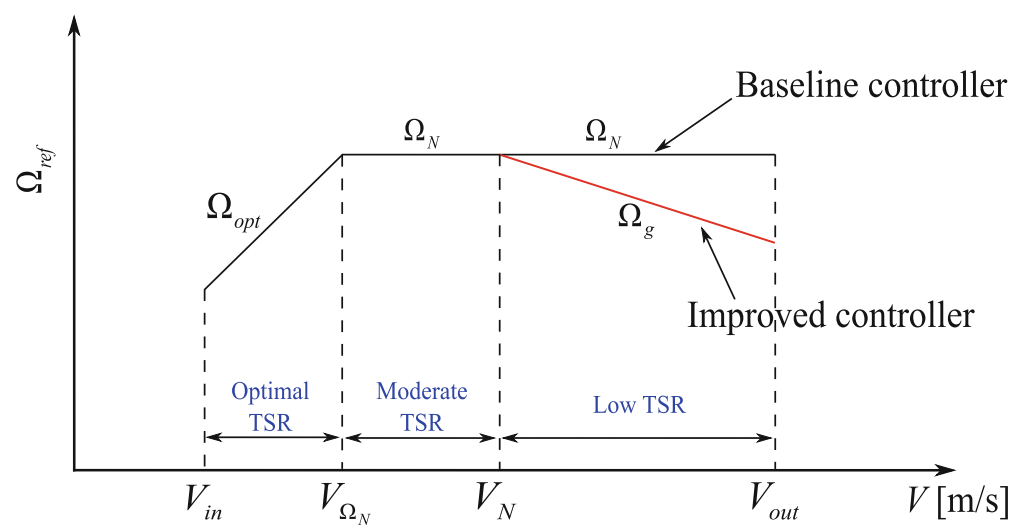

Fig. 12.5 The relationship between the reference rotor rotational speed and the wind speed for the baseline and improved controllers. $V_{i n}, V_{N}$ and $V_{\text {out }}$ are the cut-in, rated, and cut-out wind speed, respectively; $V_{\Omega N}$ is the wind speed for the rated rotational speed; $\Omega_{N}$ is the rated rotational speed; $\Omega_{\text {opt }}$ is the optimal rotational speed that can maximize the power capture; $\Omega_{g}$ is the rotational speed that can hold the mean generator power approximately constant (Cheng et al. 2016b)

not larger than the rated one. However, the control targets in region III shift to limit the aerodynamic loads acting on the rotor by limiting the rotational speed. In this case, the rotor rotates at relatively low tip speed ratios and two control strategies, as illustrated in Fig. 12.5, are considered here.

Based on these two control strategies, two controller were developed, namely i.e. the baseline controller and improved controller. This baseline controller is capable of maximizing the power capture for wind speeds below $\mathrm{V}_{\Omega \mathrm{N}}$ and maintaining the rotational speed for wind speeds above $\mathrm{V}_{\Omega \mathrm{N}}$, while the improved controller aims to maximize the power capture for wind speeds below $\mathrm{V}_{\mathrm{N}}$ and maintain the power capture approximately constant for the above rated wind speeds.

Both the baseline and improved controllers were implemented in the fully coupled codes. Figure 12.6 shows the mean generator power and thrust of a $5 \mathrm{MW}$ Darrieus rotor with different controller. Above the rated wind speed, the improved controller successfully maintains the mean generator power approximately constant. Detailed information on the discrepancies between these two controllers is provided by Cheng et al. (2016b, 2016c).

\subsubsection{Verification of the Fully Coupled Codes}

The code SIMO-RIFLEX-DMS is developed by Wang et al. (2013) and verified by validating each module separately; the code SIMO-RIFLEX-AC is developed by Cheng et al. (2016b) and verified by a series of comparisons with the codes SIMORIFLEX-DMS and HAWC2. Considering an equivalent landbased 5 MW Darrieus rotor, these three codes are verified with each other by comparing the thrust, side force and aerodynamic torque in steady wind conditions, as shown in Figs. 12.7 

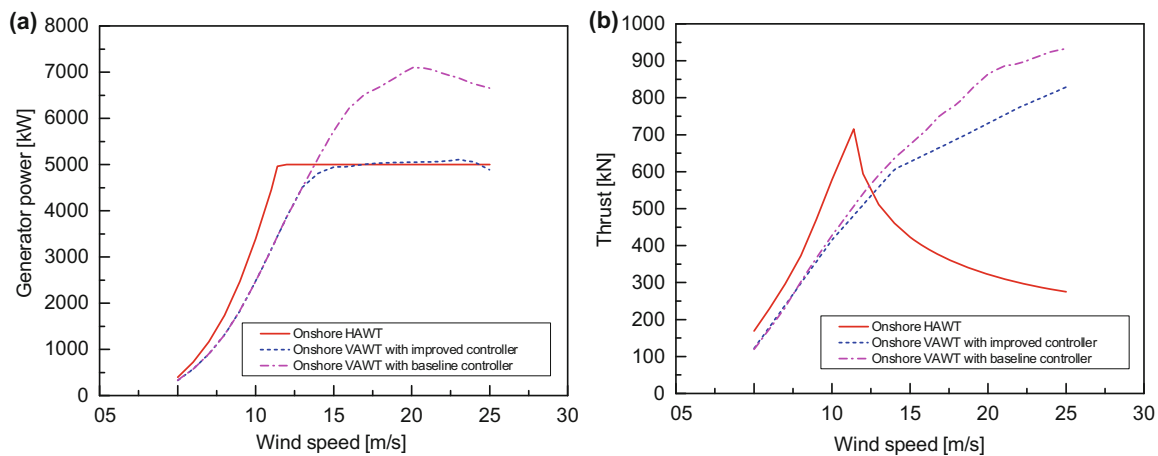

Fig. 12.6 Steady-state mean generator power and thrust of the onshore HAWT and VAWT with different control strategies (Cheng et al. 2016c)
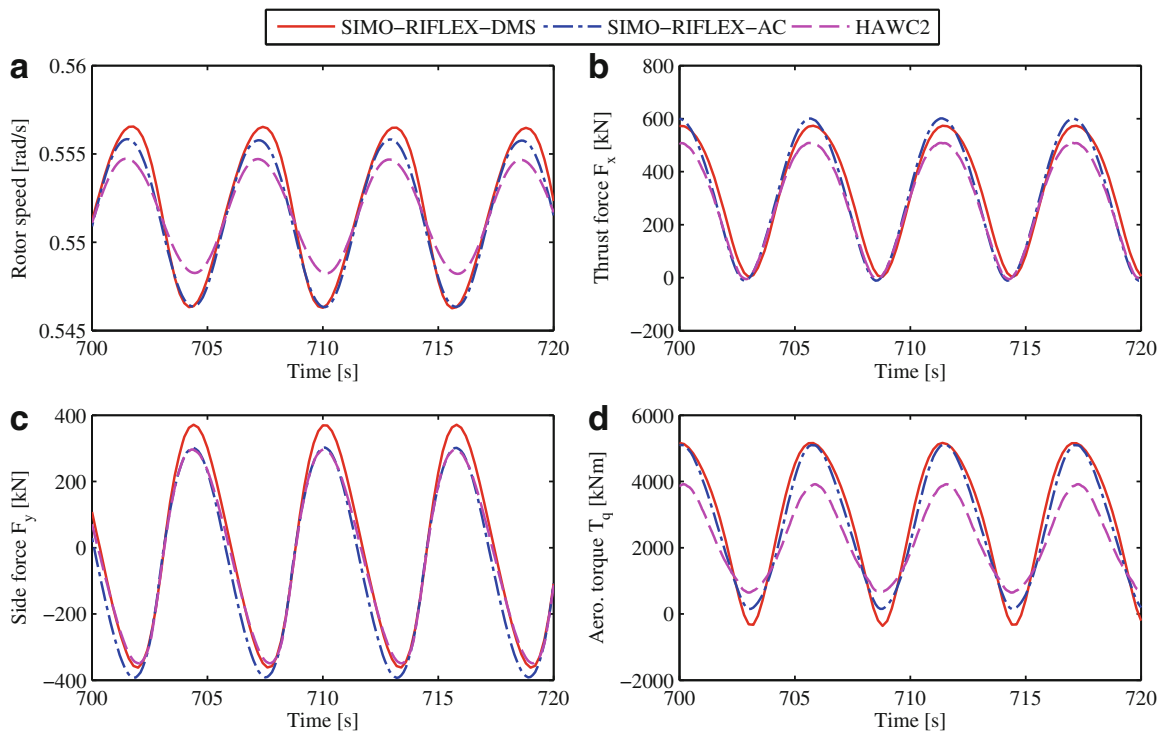

Fig. 12.7 Comparison of the rotational speed, thrust, side force and aerodynamic torque of the landbased VAWT using three codes without considering the effect of dynamic stall in the steady wind case with a wind speed of $8 \mathrm{~m} / \mathrm{s}$ (Cheng et al. 2016b)

and 12.8. The load cases shown in these two figures correspond to a tip speed ratio of 4.39 and 2.51, which locate in region I and II as illustrated in Fig. 12.5, respectively. Here the effect of dynamic stall is not included since these three codes use different dynamic stall models. The developed codes SIMO-RIFLEX-DMS and SIMO-RIFLEX-AC are accurate enough in predicting the aerodynamic loads for landbased VAWTs. Essential differences among these three codes are also revealed and presented by Cheng et al. (2016b). 

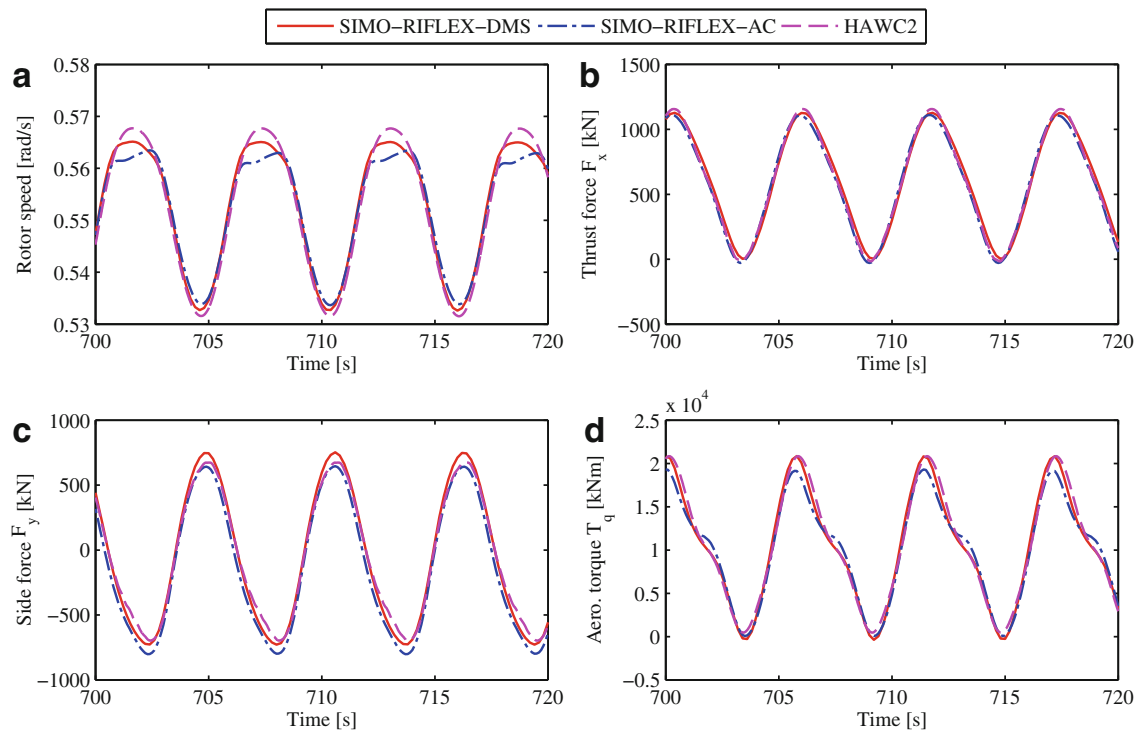

Fig. 12.8 Comparison of the rotational speed, thrust, side force and aerodynamic torque of the landbased VAWT using three codes without considering the effect of dynamic stall in the steady wind case with a wind speed of $14 \mathrm{~m} / \mathrm{s}$ (Cheng et al. 2016b)
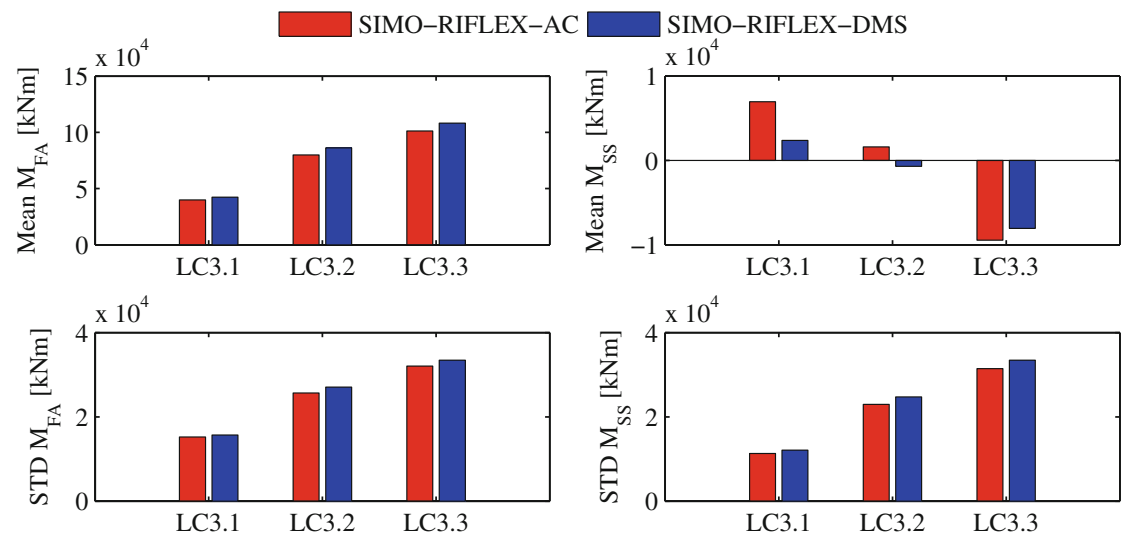

Fig. 12.9 Mean values and standard deviations of tower base fore-aft bending moment $\mathrm{M}_{\mathrm{FA}}$ and side-side bending moment $\mathrm{M}_{\mathrm{SS}}$ of the semi VAWT simulated using SIMO-RIFLEX-AC and SIMORIFLEX-DMS. The load cases are described by Cheng et al. (2016b)

In addition, the semi VAWT described in Sect. 12.2 is used to verify the capability of the codes SIMO-RIFLEX-DMS and SIMO-RIFLEX-AC in modeling and dynamic analysis of floating VAWTs. Figure 12.9 demonstrates the mean value and standard deviation of the tower base fore-aft and side-side bending moment for 
the semi VAWT. It is found that the code SIMO-RIFLEX-AC can to some extent predict more accurate dynamic responses than the code SIMO-RIFLEX-DMS.

\subsection{Dynamic Response Characteristics of Three Floating VAWTs}

The stochastic dynamic responses of the three floating VAWT concepts (Cheng et al. 2015c), as described in Sect. 12.2, are studied under the turbulent wind and irregular wave conditions, including the generator power production, global platform motion, tower base fore-aft and side-side bending moments and tensions in mooring lines. The baseline controller is used during the simulations. Detailed descriptions of load cases used can be found in Cheng et al. (2015c). It should be noted that the stochastic dynamic responses in this section are calculated using the code SIMO-RIFLEX-DMS, and the results are plotted with the mean wind speed as the variable in the abscissa axis for simplicity.

Figure 12.10 shows the mean values of the generator power production of the three floating VAWT concepts. The error bar indicates the standard deviation from the mean value. It can be observed that the mean generator powers increase as the wind speed increases. At rated wind speed of $14 \mathrm{~m} / \mathrm{s}$, the mean generator powers slightly exceed the rated power of $5 \mathrm{MW}$, since the Beddoes-Leishman dynamic stall model is included in the DMS model. The rotor considered can achieve a rated power of $5 \mathrm{MW}$ when excluding the dynamic stall effect. In addition, the mean

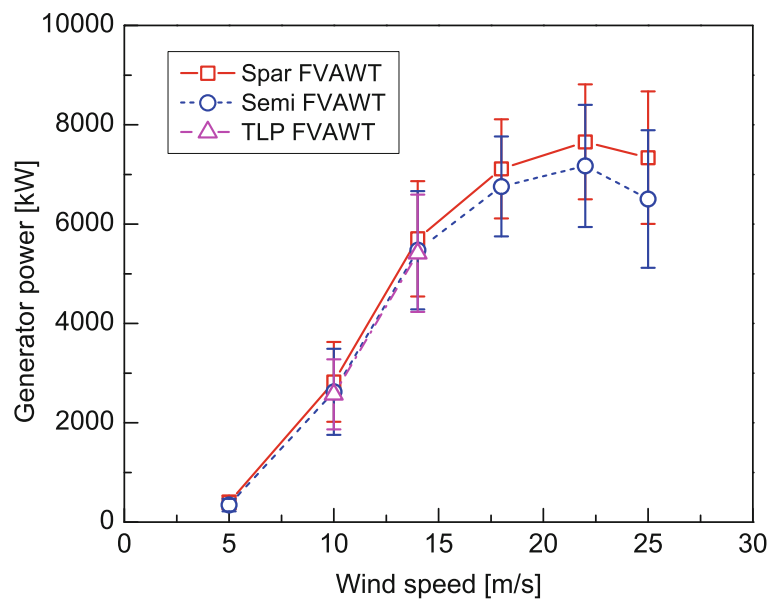

Fig. 12.10 Mean power production for the three floating VAWT concepts with error bar indicating the standard deviation from the mean value in the turbulent wind and irregular wave load cases. The load cases are indicated using mean wind speed in the abscissa axis. Results of the TLP VAWT are only given in load cases with wind speeds of 10 and $14 \mathrm{~m} / \mathrm{s}$ (Cheng et al. 2015c) 
generator power of the three floating VAWT concepts is very close to each other, except at high wind speeds where the mean generator power of the semi VAWT begins to differ from that of the spar VAWT. The difference results from the different rotational speed and increases as the wind speed increases. The different rotational speeds for the three concepts are due to the implemented controller. The controller regulates the rotational speed by adjusting the generator torque, but fails to keep the rotational speed at above rated wind speed exactly constant. The variations of the generator power for the three floating VAWT concepts are very close to each other as well.

The global platform motions of the three floating VAWT concepts present significant differences. The mean values of platform motions increase as the wind speed increases, since the mean values are mainly wind-induced. For each load case, the spar VAWT suffers the considerable larger platform motions in surge and pitch. But the standard deviations of the spar VAWT and semi VAWT in pitch motions are very close to each other. Regarding the yaw motion, the mean yaw motions of the three floating VAWT concepts are fairly close. However, the standard deviation of the yaw motion of the semi VAWT is relatively larger than that of the spar VAWT, this is due to the resonant yaw motions excited by the turbulent wind.

Characteristic structural responses for the three floating VAWT concepts are also of great interest. Here both the tower base fore-aft bending moment $\mathrm{M}_{\mathrm{FA}}$ and side-side bending moment $\mathrm{M}_{\mathrm{SS}}$ are chosen as the primary structural performance parameters. The tower base was assumed to be located below the bearings between the rotating shaft and the drive train shaft. Since the aerodynamic loads of each blade varies with the azimuthal angle, not only $\mathrm{M}_{\mathrm{FA}}$ but also $\mathrm{M}_{\mathrm{SS}}$ have great variations, which is quite different from the horizontal axis wind turbine. These variations of bending moments can cause large stress fluctuations, thus leading to great fatigue damage. Figure 12.11 compares the power spectra of $\mathrm{M}_{\mathrm{FA}}$ and $\mathrm{M}_{\mathrm{SS}}$ under the turbulent wind and irregular wave condition. The turbulent winds excite the certain low-frequency response of $\mathrm{M}_{\mathrm{FA}}$, but the wind-induced response is much smaller than the $2 \mathrm{P}$ response in both $\mathrm{M}_{\mathrm{FA}}$ and $\mathrm{M}_{\mathrm{Ss}}$. Furthermore, since the taut tendons cannot absorb the $2 \mathrm{P}$ aerodynamic excitations for the TLP VAWT, the $2 \mathrm{P}$ responses in $\mathrm{M}_{\mathrm{FA}}$ and $\mathrm{M}_{\mathrm{SS}}$ of the spar VAWT and semi VAWT are much smaller than that of the TLP VAWT, which implies that the catenary mooring system can greatly mitigate the $2 \mathrm{P}$ effects on structural dynamic responses. Eigen-frequency analysis has been carried out for this rotor and states that the natural frequencies of the first and second tower base bending modes are far away from the $1 \mathrm{P}$ and 2P excitations (Wang et al. 2013). As a consequence, the standard deviations of $\mathrm{M}_{\mathrm{FA}}$ and $\mathrm{M}_{\mathrm{SS}}$ for the spar VAWT and the semi VAWT are smaller than those of the TLP VAWT. 

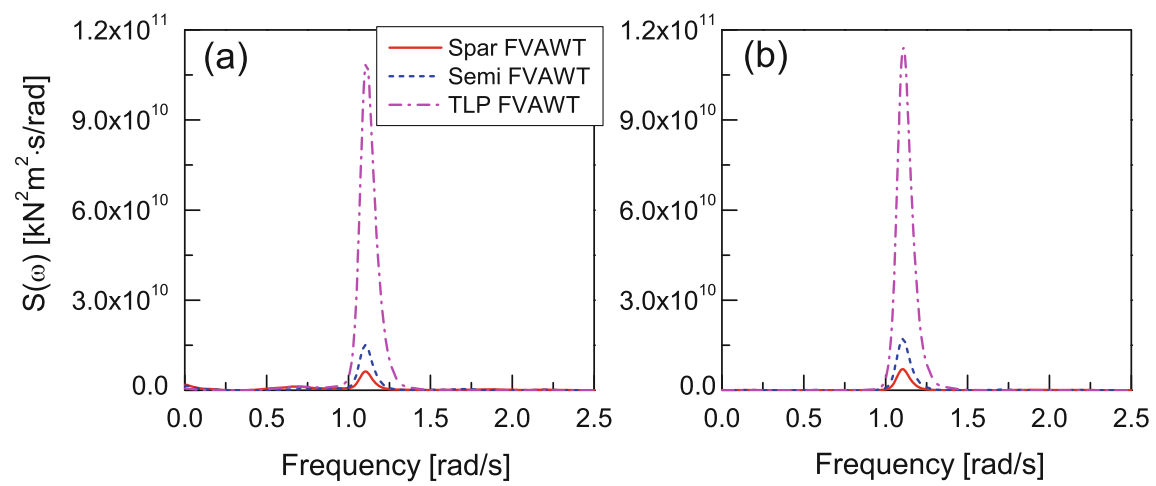

Fig. 12.11 Power spectra of tower base (a) fore-aft bending moment and (b) side-side bending moment for the three floating VAWT concepts in turbulent wind and irregular wave condition with $U w=14 \mathrm{~m} / \mathrm{s}, H s=3.62 \mathrm{~m}, T p=10.29 \mathrm{~s}$

\subsection{Comparative Study of Floating HAWTs and VAWTs}

In this section, comparative studies on the dynamic responses of floating HAWTs and VAWTs are briefly discussed. The rotors considered are the NREL 5 MW wind turbine (Jonkman et al. 2009) and the 5 MW Darrieus rotor (Vita 2011). The code SIMO-RIFLEX-DMS and SIMO-RIFLEX-AeroDyn are used to conduct the fully coupled analysis for the floating VAWTs and HAWTs, respectively.

\subsubsection{Semi HAWT vs. Semi VAWT}

Wang et al. (2014b) studied the dynamics of the semi-type HAWT and VAWT with the OC4 semi-submersible supporting the NREL 5 MW wind turbine (Jonkman et al. 2009) and the 5 MW Darrieus rotor (Vita 2011). Regarding the semi VAWT, the baseline controller described in Sect. 12.3.4 was adopted in the simulations. Thus the generator power production of the semi VAWT exceeds $5 \mathrm{MW}$ and is much larger than that of the semi HAWT above the rated wind speed. Other details with respect to the floating wind turbine systems and load cases can be found in Wang et al. (2014b).

The effect of $2 \mathrm{P}$ frequency on the structural responses, for instance the tower base bending moment, was identified for the semi VAWT. Moreover, power spectral analysis shows that the $2 \mathrm{P}$ response dominates the tower base fore-aft and sideside bending moment. Regarding the platform motions, the semi HAWT and VAWT have very close mean values and standard deviations in the pitch motion at low wind speeds. Power spectral analysis also reveals that the pitch motion of the semi VAWT has a smaller pitch resonant response and wave frequency response as well as a significantly notable $2 \mathrm{P}$ response, as demonstrated in Fig. 12.12. 


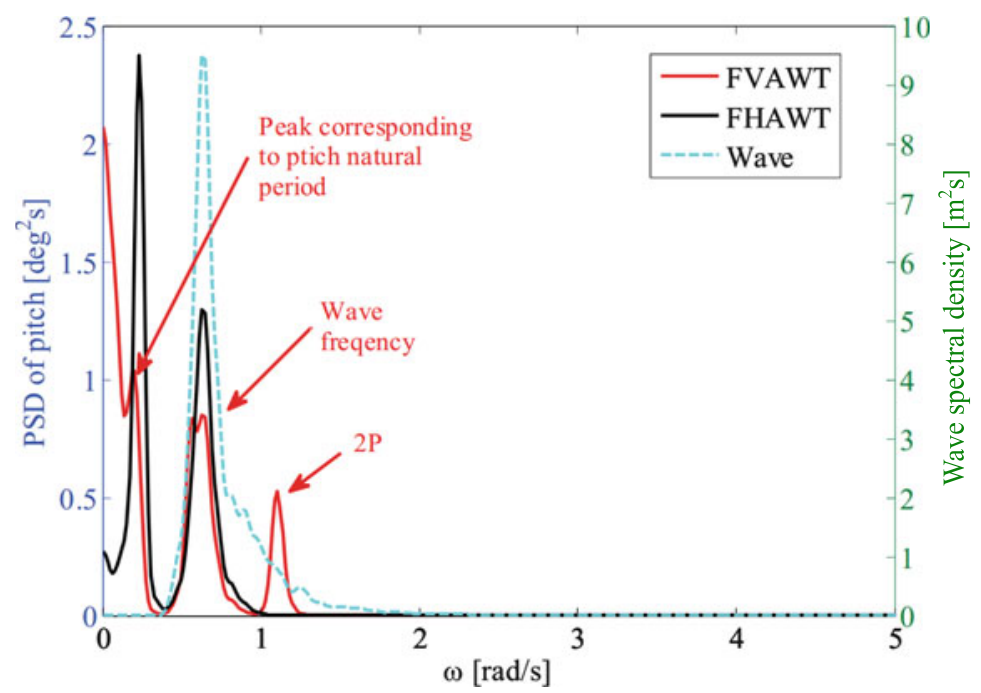

Fig. 12.12 Power spectra of the pitch motion of the semi HAWT and VAWT in turbulent wind and irregular wave condition with $U w=14 \mathrm{~m} / \mathrm{s}, H s=3.62 \mathrm{~m}, T p=10.29 \mathrm{~s}$

\subsubsection{Spar HAWT vs. Spar VAWT}

Comparative study of floating HAWTs and VAWTs was further extended to the spar-type concepts by Cheng et al. (2015b, 2016c). The OC3 spar buoy was used to support the aforementioned two rotors. Cheng et al. (2015b) conducted the comparative study using the baseline control strategy for the spar VAWT. To make the comparative study more reasonable, an improved control strategy was employed, as described in Sect. 12.3.4 (Cheng et al. 2016c). A series of numerical simulations were carried out under the turbulent wind and irregular wave conditions.

Figure 12.13 shows the mean values and standard deviations of the generator power and thrust for the spar HAWT and VAWT. The response curves are plotted using the mean values with the error bar showing one standard deviation from the mean value. At wind speeds above $14 \mathrm{~m} / \mathrm{s}$, the mean generator powers of the spar HAWT and VAWT are very close to the rated power of $5 \mathrm{MW}$. However, the standard deviation of the generator power of the spar VAWT is approximately twice of that of the spar HAWT. For wind speeds below $14 \mathrm{~m} / \mathrm{s}$, the mean generator power of the spar HAWT is always much greater than that of the spar VAWT due to the higher power coefficient.

The spar HAWT and VAWT also differ in the platform motions due to the different aerodynamic loads and control strategies. For both the spar HAWT and VAWT, the trends in the mean values of the surge, heave and pitch are very similar to those of the mean thrust acting on the rotors, since the mean values of the platform motions are mainly related to wind thrust force. The mean values of the sway, roll 

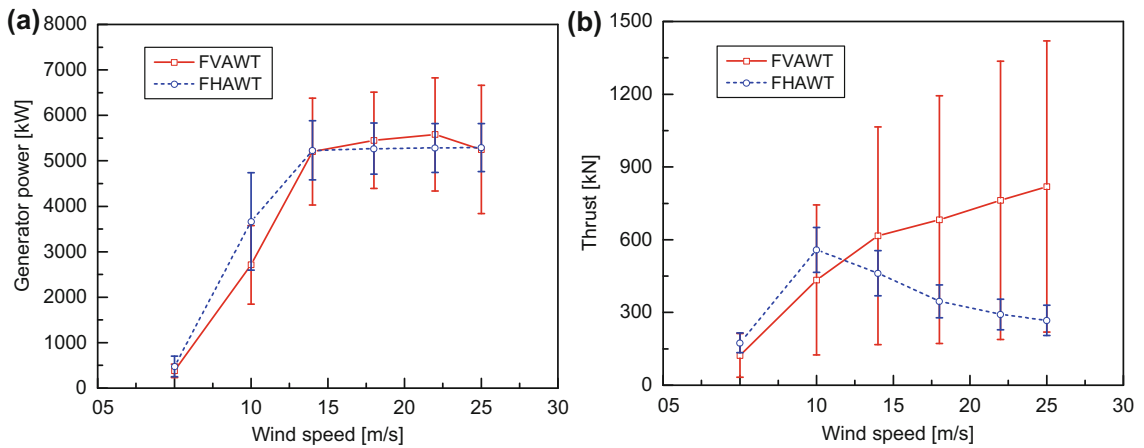

Fig. 12.13 Mean values and standard deviations of (a) generator power and (b) thrust for the spar type HAWT and VAWT under turbulent wind conditions. The error bar indicates the standard deviation

(a)

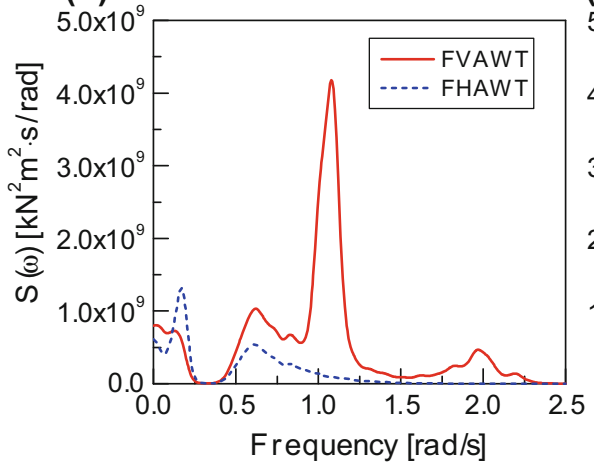

(b)

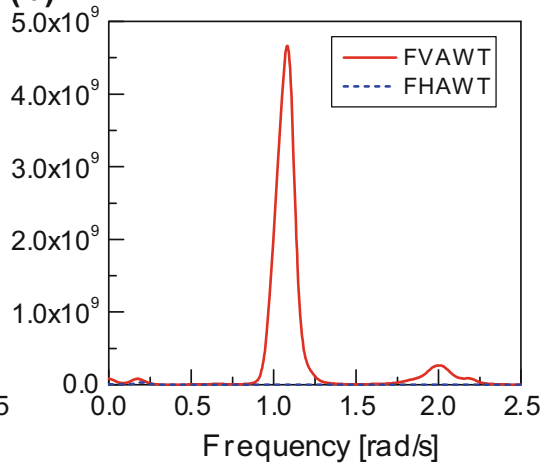

Fig. 12.14 Power spectra of the tower base (a) fore-aft bending moment and (b) side-side bending moment for the spar HAWT and VAWT in turbulent wind and irregular wave condition with $U w=14 \mathrm{~m} / \mathrm{s}, H s=3.62 \mathrm{~m}, T p=10.29 \mathrm{~s}$

and yaw motions of the spar HAWT are very small, because the aerodynamic lateral force and yaw moment are small due to symmetry. However, the spar VAWT has much larger mean values in sway, roll and yaw motions, especially at high wind speed.

The structural responses of the spar HAWT and VAWT illustrate significant differences as well. Figure 12.14 shows the power spectra of the tower base fore-aft and side-side bending moment for the spar HAWT and VAWT in turbulent wind and irregular wave condition with $\mathrm{Uw}=14 \mathrm{~m} / \mathrm{s}, \mathrm{Hs}=3.62 \mathrm{~m}, \mathrm{Tp}=10.29 \mathrm{~s}$. Obviously the response corresponding to the $2 \mathrm{P}$ frequency is considerably dominating in the tower base fore-aft and side-side bending moments for the spar VAWT. Moreover, the tower base fore-aft bending moment for the spar VAWT also includes prominent low-frequency turbulent wind induced response and wave frequency response. With respect to the spar HAWT, the tower base fore-aft bending moment consists of 


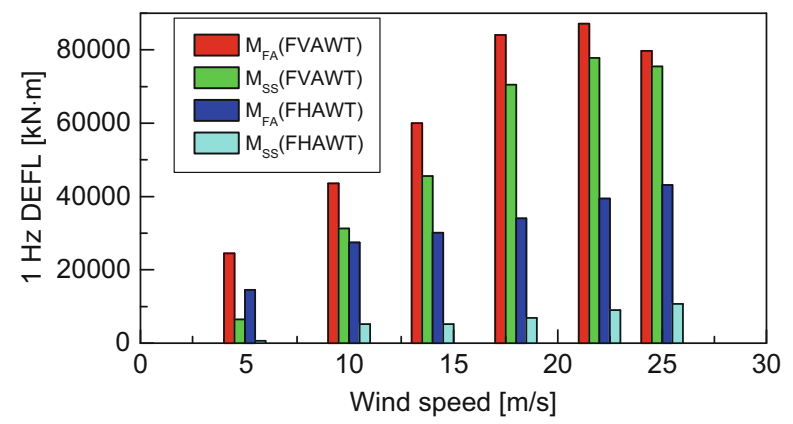

Fig. 12.15 $1 \mathrm{~Hz}$ damage equivalent fatigue loads (DEFLs) of the tower base fore-aft bending moment $\left(\mathrm{M}_{\mathrm{FA}}\right)$ and side-side bending moment $\left(\mathrm{M}_{\mathrm{SS}}\right)$ for the spar HAWT and VAWT

significant low-frequency turbulent wind induced response, pitch resonant response and wave frequency response. The pitch resonant response mainly results from the relatively large platform pitch motion. In addition, the tower base of the spar HAWT is mainly affected by the fore-aft bending moment, while the side-to-side bending moment can be neglected.

The tower base of the spar VAWT will suffer relatively larger fatigue damage than that of the spar HAWT, as shown in Fig. 12.15. A Matlab-based computer program MLife developed by NREL (Hayman 2012) is used to estimate the shortterm damage equivalent fatigue loads (DEFLs). The DEFL of the fore-aft bending moment for the spar VAWT above the rated wind speed is approximately twice that of the spar HAWT. Moreover, the DEFL of the side-side bending moment for the spar VAWT is more than six times greater than that of the spar HAWT.

\subsection{Conclusions}

This paper deals with the integrated modeling methodology for a floating vertical axis wind turbine (VAWT) system and reveals the dynamic response characteristics of representative floating VAWTs.

Firstly two fully coupled simulation tools, namely SIMO-RIFLEX-DMS and SIMO-RIFLEX-AC, are briefly introduced so as to assess the dynamic performance of typical floating VAWT concepts. These two simulation tools are based on the double multi-streamtube (DMS) method and actuator cylinder (AC) flow method, respectively. Moreover, they are capable of accounting for the turbulent inflow, aerodynamics, hydrodynamics, structural elasticity and controller dynamics. Validations of the aerodynamic module using experimental data and verifications of the fully coupled tools using a series of code-to-code comparisons are also presented. 
The dynamic responses of three floating VAWT concepts are then studied. A spar, semi-submersible and TLP floater is used to support a two-bladed Darrieus rotor, respectively. Stochastic dynamic response analysis reveals that $2 \mathrm{P}$ effects resulting from the $2 \mathrm{P}$ aerodynamic loads are prominent in the dynamic responses of these concepts. Due to the compliant catenary mooring systems, the spar and the semisubmersible can help to mitigate the $2 \mathrm{P}$ effects on structural loads and mooring line tensions as compared to the TLP concept, at the cost of larger platform motions. The TLP is not a good substructure for vertical axis wind turbine unless the cyclic variation of aerodynamic loads is significantly reduced.

Comparative studies on the dynamics of floating VAWTs and HAWTs are also demonstrated. Due to different aerodynamic load characteristics and control strategies, the spar VAWT results in larger mean tower base bending moments and mooring line tensions above the rated wind speed. Because significant $2 \mathrm{P}$ aerodynamic loads act on the spar VAWT, the generator power, tower base bending moments and delta line tensions show prominent $2 \mathrm{P}$ variation. Consequently the spar VAWT suffers severe fatigue damage at the tower bottom. The semi VAWT shows significant $2 \mathrm{P}$ variations in structural responses as well.

Acknowledgments The authors would like to acknowledge the financial support from the EU FP7 project MARE WINT (project NO. 309395) and Research Council of Norway through the Centre for Ships and Ocean Structures (CeSOS) and Centre for Autonomous Marine Operations and Systems (AMOS) at the Department of Marine Technology, Norwegian University of Science and Technology (NTNU), Trondheim, Norway. The first author would also thank Dr. Kai Wang from Aker Solutions for his valuable comments and discussions.

Open Access This chapter is distributed under the terms of the Creative Commons AttributionNonCommercial 4.0 International License (http://creativecommons.org/licenses/by-nc/4.0/), which permits any noncommercial use, duplication, adaptation, distribution and reproduction in any medium or format, as long as you give appropriate credit to the original author(s) and the source, provide a link to the Creative Commons license and indicate if changes were made.

The images or other third party material in this chapter are included in the work's Creative Commons license, unless indicated otherwise in the credit line; if such material is not included in the work's Creative Commons license and the respective action is not permitted by statutory regulation, users will need to obtain permission from the license holder to duplicate, adapt or reproduce the material.

\section{References}

Akimoto H, Tanaka K, Uzawa K (2011) Floating axis wind turbines for offshore power generationa conceptual study. Environ Res Lett 6(4):044017. doi:10.1088/1748-9326/6/4/044017

Borg M, Collu M (2014) A comparison on the dynamics of a floating vertical axis wind turbine on three different floating support structures. Energy Procedia 53:268-279. doi:10.1016/j.egypro.2014.07.236

Borg M, Collu M, Brennan FP (2013) Use of a wave energy converter as a motion suppression device for floating wind turbines. Energy Procedia 35:223-233. doi:10.1016/j.egypro.2013.07.175 
Borg M, Collu M, Kolios A (2014a) Offshore floating vertical axis wind turbines, dynamics modelling state of the art. Part II: mooring line and structural dynamics. Renew Sustain Energy Rev. doi:10.1016/j.rser.2014.07.122

Borg M, Shires A, Collu M (2014b) Offshore floating vertical axis wind turbines, dynamics modelling state of the art. Part I: aerodynamics. Renew Sustain Energy Rev. doi:10.1016/j.rser.2014.07.096

Borg M, Wang K, Collu M et al (2014c) A comparison of two coupled model of dynamics for offshore floating vertical axis wind turbines (VAWT). Paper presented at the 33rd international conference on ocean, offshore and arctic engineering, ASME, San Francisco, 8-13 June 2014

Cahay M, Luquiau E, Smadja C (2011) Use of a vertical wind turbine in an offshore floating wind farm. Paper presented at the offshore technology conference, Houston, 2-5 May 2011

Cheng Z, Wang K, Gao Z et al (2015a) Dynamic modelling and analysis of three floating wind turbine concepts with vertical axis rotor. In: Chung JS, Vorpahl F, Hong SY et al (eds) The proceedings of the 25th (2015) international ocean and polar engineering conference, Kona, June 2015. ISOPE, California, $\mathrm{p} 415$

Cheng Z, Wang K, Gao Z et al (2015b) Comparative study of spar type floating horizontal and vertical axis wind turbines subjected to constant winds. Paper presented at the Offshore 2015. European Wind Energy Association, Copenhagen, 10-12 March 2015

Cheng Z, Wang K, Gao Z, Moan T (2015c) Dynamic response analysis of three floating wind turbine concepts with a two-bladed Darrieus rotor. J Ocean Wind Energy 2(4):213-222. doi:10.17736/jowe.2015.jcr33

Cheng Z, Madsen HA, Gao Z et al (2016a) Aerodynamic modeling of floating vertical axis wind turbines using the actuator cylinder method. Submitted to Energy Procedia

Cheng Z, Madsen HA, Gao Z, Moan T (2016b) A fully coupled method for numerical modeling and dynamic analysis of floating vertical axis wind turbines. Submitted to Renewable Energy

Cheng Z, Wang K, Gao Z, Moan T (2016c) A comparative study on dynamic responses of spar-type floating horizontal and vertical axis wind turbines. Wind Energy (accepted)

Collu M, Borg M, Shires A et al (2013) FloVAWT: progress on the development of a coupled model of dynamics for floating offshore vertical axis wind turbines. Paper presented at the 32nd international conference on ocean, offshore and arctic engineering, ASME, Nantes, 9-14 June 2013

Dabiri JO (2011) Potential order-of-magnitude enhancement of wind farm power density via counter-rotating vertical-axis wind turbine arrays. J Renew Sustain Energy 3(4):043-104. doi: $10.1063 / 1.3608170$

Faltinsen OM (1995) Sea loads on ships and offshore structures. Cambridge University Press, Cambridge

Hayman G (2012) Mlife theory manual for version 1.00. In: National Renewable Energy Laboratory National Wind Technology Center (NWTC) Information Portal. Available via NWTC. https://nwtc.nrel.gov/system/files/MLife_Theory.pdf. Accessed 09 Apr 2016

Jonkman JM, Butterfield S, Musial W et al (2009) Definition of a 5-mw reference wind turbine for offshore system development: Tech. Rep. NREL/TP-500-38060. In: NREL publications. Available via NREL. http://www.nrel.gov/docs/fy09osti/38060.pdf. Accessed 09 Apr 2016

Larsen TJ, Madsen HA (2013) On the way to reliable aeroelastic load simulation on VAWT's. Paper presented at the European Wind Energy Conference and Exhibition (EWEA), Austria, 4-7 February 2013

Luxcey N, Ormberg H, Passano E (2011) Global analysis of a floating wind turbine using an aerohydro-elastic numerical model: Part 2: benchmark study. Paper presented at the ASME 2011, 30th international conference on ocean, offshore and arctic engineering, Rotterdam, 19-24 June 2011

Madsen HA (1982) The actuator cylinder: a flow model for vertical axis wind turbines. Technical Report, Institute of Industrial Constructions and Energy Technology, Aalborg University Centre, Aalborg

MARINTEK (2012a) RIFLEX theory manual, version 4.0. Norwegian Marine Technology Research Institute, Trondheim 
MARINTEK (2012b) SIMO theory manual version 4.0. Norwegian Marine Technology Research Institute, Trondheim

Ormberg H, Passano E, Luxcey N (2011) Global analysis of a floating wind turbine using an aerohydro-elastic model: Part 1 code development and case study. Paper presented at the ASME 2011, 30th international conference on ocean, offshore and arctic engineering, Rotterdam, 1924 June 2011

Owens B, Hurtado JE, Paquette JA et al (2013) Aeroelastic modeling of large off-shore verticalaxis wind turbines: development of the offshore wind energy simulation toolkit. Paper presented at the 54th AIAA/ASME/ASCE/AHS/ASC structures, structural dynamics and materials co-located conferences, Boston, 8-11 April 2016

Paquette J, Barone M (2012) Innovative offshore vertical-axis wind turbine rotor project. Paper presented at the EWEA 2012 annual event, Copenhagen, 16-19 April 2012

Paraschivoiu I (2002) Wind turbine design: with emphasis on Darrieus concept. Polytechnic International Press, Montreal

Paulsen US, Madsen HA, Hattel JH et al (2013) Design optimization of a $5 \mathrm{mw}$ floating offshore vertical-axis wind turbine. Energy Procedia 35:22-32. doi:10.1016/j.egypro.2013.07.155

Vita L (2011) Offshore floating vertical axis wind turbines with rotating platform. Dissertation, Technical University of Denmark

Wang K, Moan T, Hansen MOL (2013) A method for modeling of floating vertical axis wind turbine. Paper presented at the 32nd international conference on ocean, offshore and arctic engineering, ASME, Nantes, 9-14 June 2013

Wang K, Hansen MOL, Moan T (2014a) Dynamic analysis of a floating vertical axis wind turbine under emergency shutdown using hydrodynamic brake. Energy Procedia 53:56-69

Wang K, Luan C, Moan T et al (2014b) Comparative study of a FVAWT and a FHAWT with a semi-submersible floater. In: Chung JS, Vorpahl F, Hong SY et al (eds) The proceedings of the 24th (2014) international ocean and polar engineering conference, Busan, June 2014. ISOPE, California, p 302

Wang K, Cheng Z, Moan T et al (2015a) Effect of difference-frequency forces on the dynamics of a semi-submersible type FVAWT in misaligned wave-wind condition. In: Chung JS, Vorpahl F, Hong SY et al (eds) The proceedings of the 25th (2015) international ocean and polar engineering conference, Kona, June 2015. ISOPE, California, p 517

Wang K, Hansen MOL, Moan T (2015b) Model improvements for evaluating the effect of tower tilting on the aerodynamics of a vertical axis wind turbine. Wind Energy 18:91-110. doi: $10.1002 /$ we. 1685

Wang K, Moan T, Hansen MOL (2016) Stochastic dynamic response analysis of a floating verticalaxis wind turbine with a semi-submersible floater. Wind Energy. doi:10.1002/we.1955 